\title{
Proposal of an Observatory of Trends for Nanotechnology in the Context of Technology Management in an Oil and Gas R\&D Center - Case: Nanotechnology
}

\author{
Viviane Masseran Antunes Parreiras', Adelaide Maria de Souza Antunes ${ }^{2}$, Lelia Lowe ${ }^{3}$
}

\begin{abstract}
The paper presents basic concepts on nanotechnology and the use of this in an oil and gas research and development (R\&D) center, the Research and Development Center Leopoldo Américo Miguez de Mello of Petrobras (CENPES). The aim of this paper is to present a proposal of an observatory of trends in the area of nanotechnology at CENPES, to generate information, such as the state of the art technologies, technological trajectories, movements of competitors and partners, and aspects relating to regulations and incentives for decision making in the technology management process. The model consists of five steps that should occur in a continuous cycle: literature review, expert consultation, analysis of opportunities and threats, timelines or roadmaps, and monitoring. In conclusion, the proposed observatory includes a set of topics (variables), sources, techniques of competitive technical intelligence and technological foresight, systematized in order to support decision making in technology management.
\end{abstract}

Keywords: observatory of trends; r\&d business center; nanotechnology.

'School of Chemistry of the Federal University of Rio de Janeiro, Program in Technology of Chemical and Biochemical Processes. CENPES/ Petrobras. E-mail: vmasseran@yahoo.com.br

${ }^{2}$ School of Chemistry, Federal University of Rio de Janeiro.

${ }^{3}$ CENPES/Petrobras.

ISSN: 07 I8-2724. (http://www.jotmi.org)

Journal of Technology Management \& Innovation @ Universidad Alberto Hurtado, Facultad de Economía y Negocios. 


\section{Introduction}

A research and development (R\&D) business center should be prepared to anticipate technological solutions for other areas of the company, enabling the company to stay ahead of the competition and, therefore, the institution need to have a technology/innovation management process well structured.

The technology management process of an institution implies the definition, prioritization, implementation and evaluation of research and development (R\&D) projects. The search for information related to movements of players and their R\&D projects, and related to signs of change and trends is important for this process, because the understanding of these aspects allows the organization to understand the current context of the organization. And the practice of reflections about future enables the institution to be better prepared against the competition for different situations in medium or long-term.

Such information may be also relevant for monitoring the technological dimension of prospective scenarios because they allow the identification of technological trends, potential disruptive technologies that influence the company's business, as well as a discussion of when this may happen within the time horizon considered in the scenarios of the organization, that can help the organization to prepare its long-term strategies.

Competitive technical intelligence, linked to the actions of the present and foresight, linked to future studies, can be used to generate this type of information. These techniques can be applied punctually by different areas or can be systematized through a structured model as proposed in this paper.

Tidd, Bessant and Pavitt (2008) comment that one of the phases of innovation management includes the analysis of the external environment. According to Leitão (1996), monitoring the external environment has become increasingly important, allowing the verification of what is happening in the environment around the organization that can impact the business, such as: i) new technologies/technological trends; ii) potential partners for research projects, iii) opportunities and threats in the short, medium and long-term; among others.

This paper is structured as follows: first, the basic concepts of nanotechnology, that is considered a technology carrier for the future, are presented. Then information about CENPES and the use of nanotechnology in the institution is shown, addressing how the nanotechnology area is organized at the research center. Later, it is proposed the model of the observatory of trends in the area of nanotechnology CENPES, composed of five steps, and finally, it is possible to find final remarks and references.

\section{Basic concepts of nanotechnology}

According to the U.S. National Nanotechnology Initiative (2000), nanotechnology involves controlling materials at dimensions of I to 100 nanometers. Alencar et al (2006) affirms that nanotechnology involves the construction and use of functional structures designed in atomic or molecular scale, measured in nanometers (one nanometer, abbreviated as $\mathrm{nm}$, is one meter divided by a billion, which means that I $\mathrm{nm}$ is equal to $10-9 \mathrm{~m}$ ).

Nanotechnology is a future carrier technology, running through different sectors of the economy, such as, according to Alves (2004): chemical and materials; pharmaceutical, biotechnology and biomedical, industrial instrumentation, power industry; environment, among others. According to Melo and Pimenta (2004), nanotechnology can cover various applications, such as nanoelectronics; drug delivery; nanomaterials; composites of polymers and ceramics and metal nanoparticles; the optical properties of nanomaterials; magnetic properties of nanomaterials.

Worldwide, the U.S. began a massive investment in nanotechnology in the late ' 90 s, with the landmark of the U.S National Nanotechnology Initiative( NNI), which supports research in nanoscale developed in departments such as the Department of Energy (DoE) and surveillance products such as the Food and Drug Administration (FDA). Europe and Asia have also invested heavily in nanotechnology, for example: Ireland, England and Japan, that have created governmental strategies for nanotechnology.

In Brazil, the Forum on Competitiveness and Innovation in Nanotechnology of Ministry of Development, Industry and Foreign Trade (MDIC), as can be seen in the website of the Ministry, was created in 2008, involving several institutions, private and public companies and government to discuss guidelines for leveraging research, products and policies for nanotechnology. In 2012, the Inter-Ministerial Committee of Nanotechnology was constituted, having as one of its goals the improvement of policies, guidelines and actions for the development of nanotechnology in the country.

In this same year, the Brazilian Ministry of Science, Technology and Innovation (MCTI), as can be seen in its website, published the National Strategy for Science, Technology and Innovation 2012-20I5 which includes guidelines for nanotechnology, such as the consolidation of national laboratories infrastructure and the support to: Thematic Networks and the National Institutes of Science and Technology (INCT); 
institutional R\&D projects; the creation of training program for human resources; development of industrial products/ processes related to nanotechnology; dissemination of nanotechnology in society; and international cooperation.

\section{CENPES and nanotechnology}

The Research and Development Center Leopoldo Américo Miguez de Mello (CENPES), Petrobras R\&D Center, reflects all business segments of Petrobras (exploration and production, refining, petrochemical, gas and energy, biofuels) and also cross-sectional areas (logistics, environment, climate change, biotechnology and nanotechnology). There are different areas, with a great diversity of dynamic technological development, some of them are more mature and traditional than others.
At CENPES, nanotechnology is defined as the intentional and controlled manipulation of matter at the scale of less than $100 \mathrm{~nm}$ to confer different properties and functions, in order to enable the application of nanotechnology to overcome the critical technological challenges of the company, seeking to find properties that offer new applications for existing materials/devices, and to develop new materials/devices.

Nanotechnology at CENPES has greater focus on nanotechnological solutions for the energy industry and adaptation of technologies developed for other segments such as medical, automotive, etc. The main findings are related to coatings, structural materials, membranes, nanoparticles, nanofluids and sensors. Currently, nanotechnology at CENPES is divided into the following areas of research: structural materials; coatings; sensors; and health, safety and environment (HSE), which includes issues related to: toxicology, life cycle analysis, and remediation, among others.

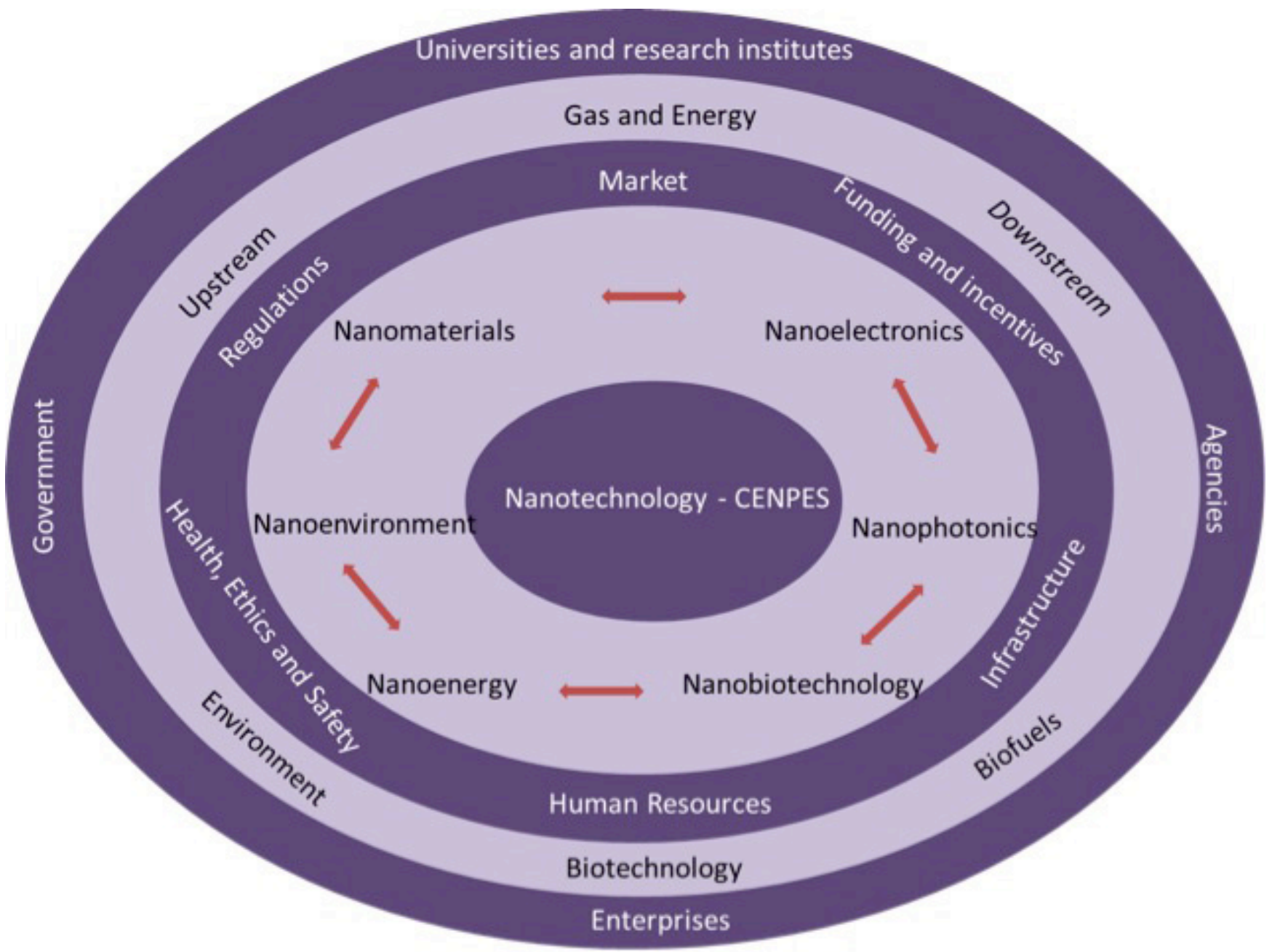

Figure I.Actors and issues related to nanotechnology - focus CENPES. Date based on:Adapted from Prospective Study Nanotechnology - Industry Notebooks Series of ABDI - Volume XX - 20I0, based on CGEE (2008)

ISSN: 07 I 8-2724. (http://www.jotmi.org)

Journal of Technology Management \& Innovation @ Universidad Alberto Hurtado, Facultad de Economía y Negocios. 
The proposed model for an observatory of trends for nanotechnology intends to help to systematize the application of competitive technical intelligence and technological foresight techniques, in order to identify the most appropriate methods for this area, as well as set the frequency of application, the participants to be involved, the form of presentation of results, among others, providing ongoing studies that generate inputs for decision making in management of the nanotechnology area.

As the differential of this model of observatory, it is important to incorporate different actors involved with nanotechnology, since CENPES operates in a context of open innovation, considering universities through thematic networks and some partner companies as well as representatives of governments and agencies, who may also have a relevant role in the discussion of trends and signs as there are issues of regulation, ethics and safety in discussion.

CENPES coordinates the Thematic Network for Nanotechnology, through which develops R\&D projects with universities and research institutions. In the area of nanotechnology, CENPES has more than 30 agreements with universities and research institutions and has also developed partnerships with companies focusing on research projects, involving not only universities and external research, but also suppliers and service providers.

Using a figure that shows the actors and issues related to nanotechnology available in Prospective Study Nanotechnology - Industry Notebooks Series of ABDI - Volume XX - 2010, based on CGEE (2008), to take a systemic view, an adjustment was made to adapted this picture to CENPES, presented in Figure I, in which are shown, from the inside out: the main applications; relevant conditioning factors; segments of oil and gas where nanotechnological solutions can be applied; and main actors involved.

\section{Proposal of a model of observatory of trends for na- notechnology area at CENPES}

According to Parreiras and Antunes (2012), in general, the observatories of trends are used to monitor specific issues and also to conduct prospective studies, using different techniques, sources and forms of participation. Thus, in order to understand better the concepts of observatories of trends, it is important to study the concepts related to competitive technology intelligence and foresight, since these activities are intrinsically related to the monitoring and analysis of the external environment, as well as prospective studies, respectively.

With respect to competitive technical intelligence, according to Klavans and Ashton (1997), it can be used in environments susceptible to disruption and technological environments that depend on developments in science and technology (S\&T). Kerr et al (2006) complement the concept, relating competitive intelligence technology to the identification of opportunities and threats of technological base.

Regarding to technological foresight, Irvine and Martin (1984) consider that technology foresight analyzes the longterm future of science and technology, economy and society in order to identify strategic areas of research and emerging technologies. And, according to Coates (1985), the foresight helps to understand the forces that shape the future and can be useful in decision-making processes.

There are several techniques that can be applied to competitive technical intelligence and also to foresight, as shown in the examples in Table I (see next page), selected based on the following authors and reports: Godet (1987), Porter et al (199I), Ashton and Klavans (1997), Coburn (1999), Miller (2002), Georghiou (2008), Ashton and Hohhof (2009) and the reports Handbook of Knowledge Society Foresight (2002) and UNIDO Technology Foresight Manual (2005). These types of techniques can, sometimes, be used in a complementary way.

Parreiras and Antunes (2012) proposed a model of observatory of trends for R\&D business centers, structured in two dimensions of horizon: current (short-term) - related to the application of competitive intelligence techniques; and future (medium and long-term) - related to foresight techniques, considering aspects as objectives, variables, information sources, scope, periodicity, indicators, resources and target public, as shown in Figure 2 (See next page).

Some issues relevant to the proposition of a model of observatory of trends in the nanotechnology area at CENPES should be taken into consideration, for example:

- It is necessary to identify the main features of the nanotechnology area at CENPES as well as its needs in terms of intelligence and foresight in order to select the methods, because according to the specific area, certain techniques may be more appropriate.

- As the area is multidisciplinary and involves different actors, may be interesting to consider, in the proposed model, techniques that involve the participation of different internal/external actors:

- Internal experts from different areas of the institution involved with nanotechnology.

- Actors/external experts - and government agencies (related to, for example, regulations, incentives, financing); universities (thematic networks) and partner companies. 


\begin{tabular}{l|l}
\hline \multicolumn{1}{|c|}{ Techniques } & \multicolumn{1}{c}{ Descriptive } \\
\hline Patent analysis & $\begin{array}{l}\text { Identification of information related to specific technologies, involving } \\
\text { patents, inventors, institutions, among others. }\end{array}$ \\
\hline SWOT analysis & $\begin{array}{l}\text { Analysis of strengths and weaknesses (internal), opportunities and threats } \\
\text { (external). }\end{array}$ \\
\hline Scenarios & $\begin{array}{l}\text { Description of coherent stories about futures. } \\
\text { of a specific field and the development of technological options. }\end{array}$ \\
\hline Roadmaps & $\begin{array}{l}\text { Research the aims the convergence of opinions, ensuring anonymity, } \\
\text { interaction and feedback controlled and should have at least two rounds. }\end{array}$ \\
\hline Delphi \\
research
\end{tabular}

Table I - Examples of competitive technical intelligence and technological foresight Data based on:Author's elaboration, based on the bibliographic review

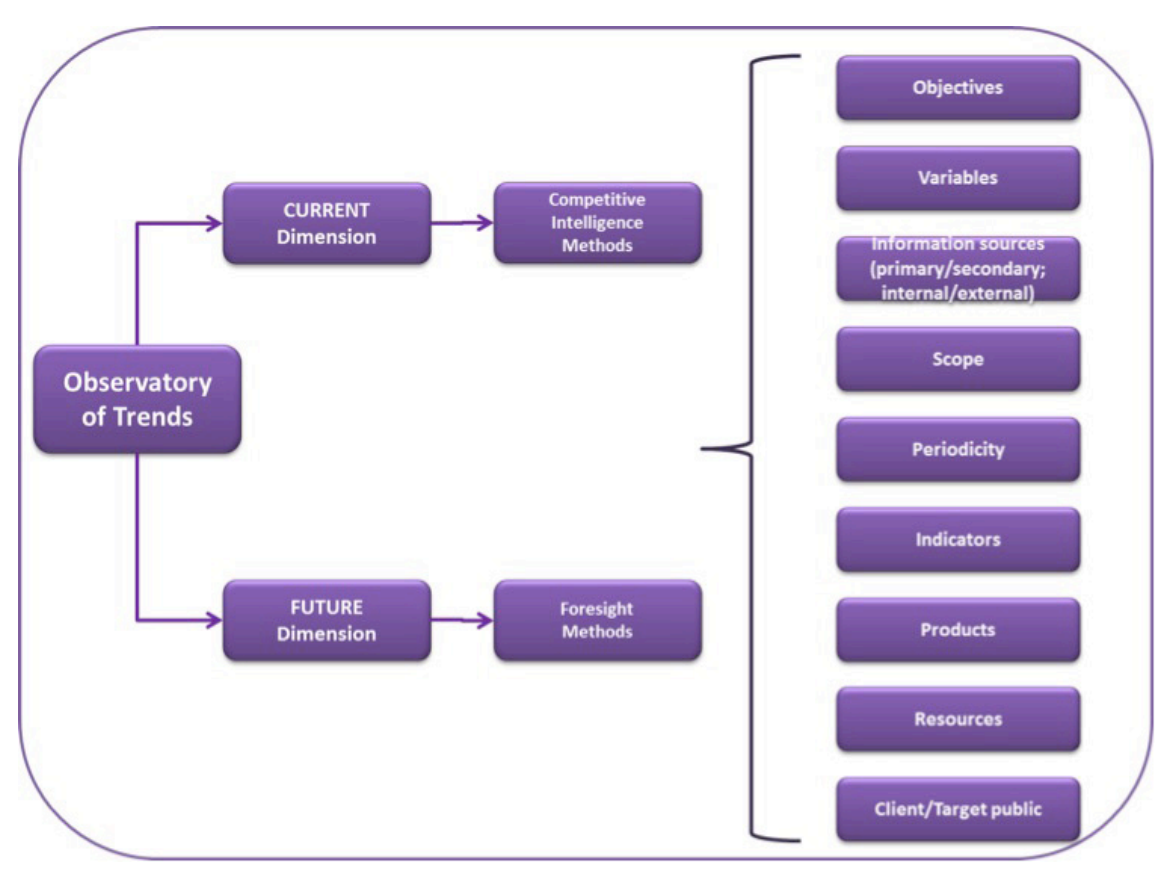

Figure 2. Model of observatory of trends in R\&D business centers. Data based on: Parreiras and Antunes (2012) 
For structuring the model of observatory of trends in the area of nanotechnology at CENPES will be used, as a base, the model proposed by Parreiras and Antunes (20I2), as it was already mentioned in Figure 2. It is worth noting that the model of observatory of trends proposed does not represent a formal area, but rather a set of systematic activities involving the application of competitive technical intelligence and technological foresight techniques.

The first step is to define the purpose of the proposed observatory. In the case of the model proposed in this paper, the purpose is: to perform studies in order to enable the understanding the state of the art of nanotechnology in Brazil and around the World and to identify signs of change and technological trends, seeking to build, in an ongoing basis, a future vision for nanotechnology at CENPES.

Besides, it is important to define the target public and the processes that should receive information from the observatory of trends that, in the case of CENPES, may be related to: definition of technological strategies, decision on technology partnerships and building the future vision.

The inputs that can be used in the construction of the model of observatory of trends specific for nanotechnology area at CENPES are: strategic guidelines for nanotechnology area at the R\&D center and interviews with actors involved with this area.
Then, it is necessary to identify the variables to be monitored, which may involve: technologies; actors (universities, companies, agencies and governments); constraints (regulations, incentives, funding, among others). After that, it's important to define the information sources and techniques of intelligence and foresight to be used as the examples shown in Figure 3.

It's worth commenting that the databases of patents, publications and reports, in general, encompass the world, while the Innovation Portal (from the Ministry of Science, Technology and Innovation) and the directory of research groups (from National Council for Scientific and Technological Development - $\mathrm{CNPq}$ ) are focused on Brazil.

Regarding competitive technical intelligence and technological foresight, it is worth noting that there are many methods that can be used and they should be selected based on some aspects: the necessities of the area where will be performed the prospective studies (in terms of objectives and expected results), deadline and time horizon.

The order of applying competitive technical intelligence and technological foresight techniques in the model of observatory of trends for nanotechnology at CENPES is presented in Figure 4, in the form of a continuous cycle.

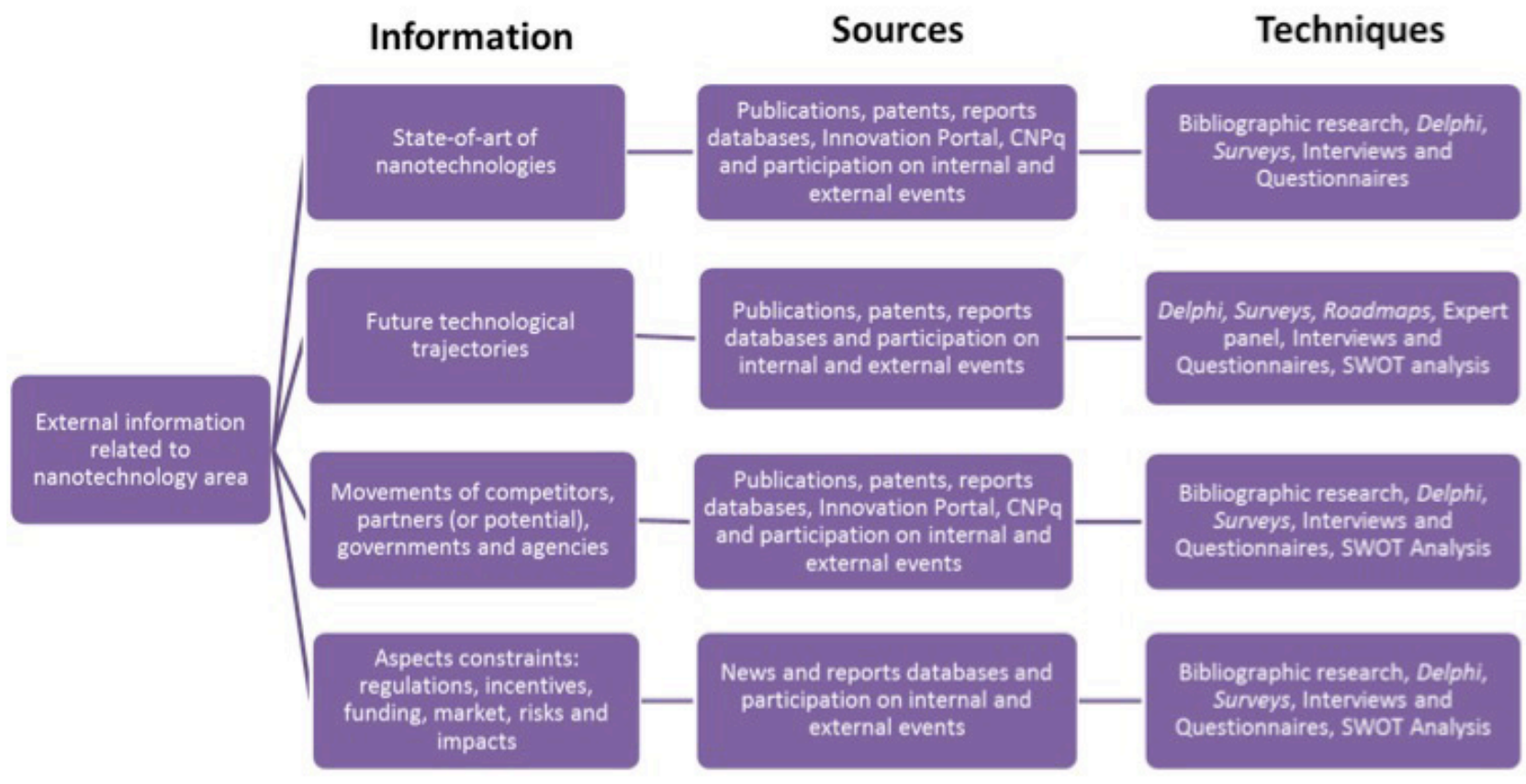

Figure 3. Examples of types of information necessary for the technological management in the area of nanotechnology at CENPES. Data based on:Authors' elaboration

ISSN: 07I 8-2724. (http://www.jotmi.org)

Journal of Technology Management \& Innovation (C) Universidad Alberto Hurtado, Facultad de Economía y Negocios. 
First, it is proposed a literature search (articles/patents/ news) for developing an overview of nanotechnology in the oil and energy industry in Brazil/World, to identify: relevant actors; major technological trends, regulations and their impacts for nanotechnology. Before starting, it is necessary to define the scope of competitive technical intelligence and prospective studies to be performed - in this case, it is proposed that it should include Brazil and World information, depending on the needs of each study.

Then, it is suggested an expert consultation with experts, including different actors (universities and research institutes, companies, agencies and governments) to identify technological trends, as well as checking other relevant issues to the area of nanotechnology at CENPES and to enrich the process. Participants must not only be experts in nanotechnology, but also in areas where nanotechnology can be applied. Different techniques can be used, according to the conditions/requirements of each study, such as delphi, survey, interviews and questionnaires, or expert panel.

The delphi research, for example, enables to get expert opinion, with the inclusion of different actors and at the same time it guarantees the anonymity, while in the case of an expert panel, some participants may be inhibited to share relevant information, although, in the case of a panel, it may be easier to promote discussions and interactions between participants. Other types of consultation can also be performed, as example, a survey or a simpler consultation that could involve questionnaires or interviews, according to the necessities of the area.
After analyzing the results of the literature research and the consultation, the opportunities and threats should be identified. Subsequently, it is suggested to build a roadmap or a timeline (as a more simplified roadmap), which allows to show the main findings of the studies, considering the impacts in horizons of short, medium and long-term. Technologies should be listed (under development or that may be developed in Brazil/World), the constraints (for example: new regulations in Brazil/World; sources of research funding, incentives, among others), and the possible movements of actors (for example: research development, prototyping, development of partnerships, among others), signaling the opportunities and threats.

Then for monitoring some relevant topics, it is suggested to prioritize the key topics (variables/questions) and to define the techniques to be used, for example, analysis of patents and papers, and meetings/contacts with internal experts involved in the issue for discussion of signs and trends and, even, consultation with external experts when necessary. It is important to say that variables monitoring is an activity that involves a continuous observation, with the publication of alerts when it's necessary.

With reference to the periodicity of the studies, it is important to remember that it depends on the purpose for which the observatory of trends is intended, the target public and the processes that should receive the results of the observatory. Thus it is suggested that, from times to times (every six months or one year, according to the area's dynamic), a revision/complement of the literature research can be con-

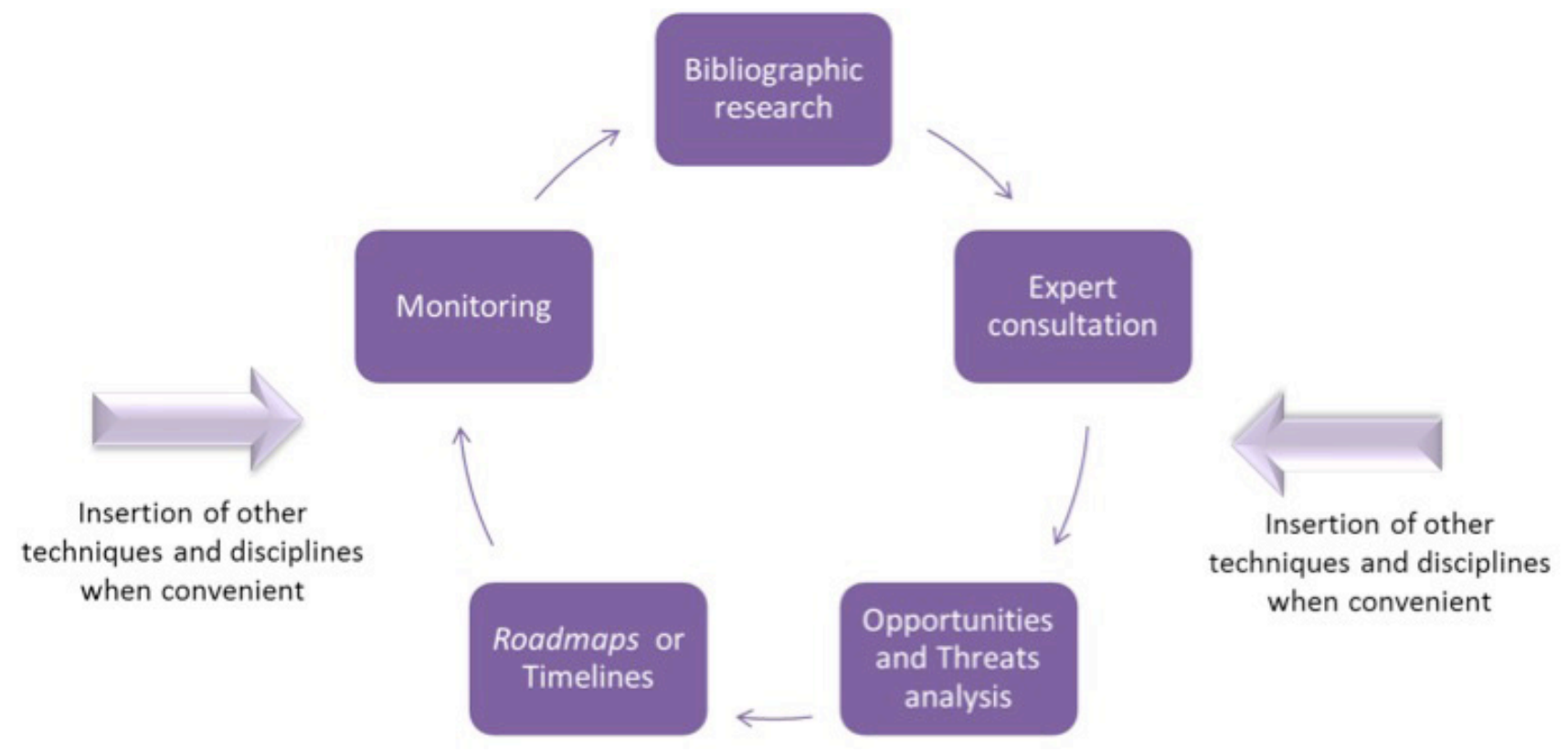

Figure 4. Proposal of model of observatory of trends in the area of nanotechnology at CENPES. Data based on:Authors' elaboration.

ISSN: 07 I8-2724. (http://www.jotmi.org)

Journal of Technology Management \& Innovation @ Universidad Alberto Hurtado, Facultad de Economía y Negocios. 
ducted. The expert consultation should happen whenever it is necessary to enrich studies or to clarify doubts and it can be done through brainstorming, questionnaires, delphi, survey, expert panel, among others, or expressly, by telephone interview, for example.

A more structured consultation can occur in a longer periodicity (as example, every one or two years, according to the technological development dynamics of the area and to the necessities of the studies), involving expert panels (internal and external participants, in the case of the external participants, the current partners and also the potential ones should be considered) can be organized, which expert considered "visionary", to allow the discussion about future technological trends in order to enrich the results of the observatory and to identify disruptive technologies. This kind of consultation may be useful, for instance, to provide inputs for future vision construction processes.

Roadmaps or timelines should be kept "alive" in the organization, being updated continuously based on monitoring information and other material obtained through the area of nanotechnology, also interfaced with other processes in the institution. For presentation of results, it is proposed the elaboration of reports, presentations and a timeline/roadmap to illustrate the findings and information obtained.
The features that should be considered are: virtual structures for consulting external experts, information databases, and internal experts that need to be involved in the process. Regarding the indicators, when necessary, some results of the research literature can be used, such as, number of patents and papers to identify possible trends.

Finally, it is important to emphasize that, in the general context, information generated by the observatory can be used not only as inputs for technology management in the R\&D center (for example: identification of key technologies to be researched, definition of technology partners, market analysis technologies/products to be developed, etc.), but also in the monitoring of the technological dimension of prospective scenarios of the institutions (for example: identification of future trends, disruptive technologies and reflections about when these issues or events could happen when effectively).

At the end of the cycle, an evaluation should be performed to identify points of improvement for the next cycle. Throughout the activities of the observatory can be inserted other techniques and disciplines/areas of expertise, as required by the area and by the studies to be conducted, mainly because nanotechnology is a multidisciplinary area, with application to different sectors.

In Figure 5, it is presented an example of presentation of the observatory results with a synthesis of technological trajectories, based on the opinion of outside experts.

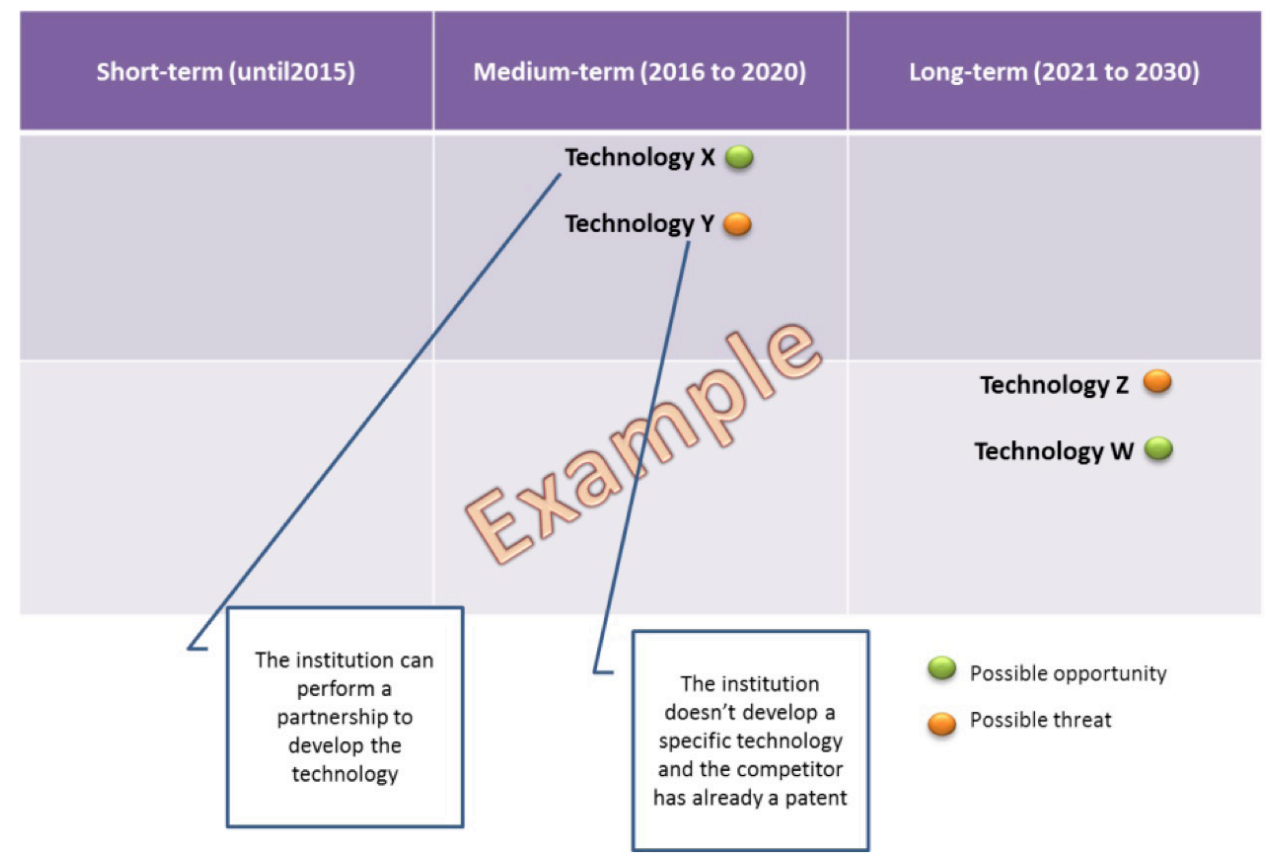

Figure 5. Synthesis of Technological Trajectories - disseminated in the World. Data based on:Authors' elaboration

ISSN: 07 I 8-2724. (http://www.jotmi.org) 
In Figure 6, it is possible to observe an example of a summary table of constraints, actors, opportunities and threats. In Figure 7, it is shown the interface between the model of the observatory (where it is performed the identification and monitoring of signals, trends and movements of actors) and the activities of technology management and monitoring of prospective scenarios at CENPES.

After the implementation of the observatory, CENPES experts will be able to use, as input, the information generated by the observatory in order to support decision making in existing processes of the R\&D center, as shown in Figure 7. Furthermore, it will be also possible to aggregate, to the results of the observatory of trends, other information obtained from analyzes performed in the technology management process, so it can complement the observatory activities.

\section{Final Considerations}

In the search for competitive advantage through innovation, organizations need to know the movements and current events of their competitors and partners, government's actions, technological trends, among others, as well as developing prospective studies to help institutions to be better prepared for the future.

In an R\&D business center, such information is relevant to the decision-making processes within the technology management and the monitoring of the technological dimension prospective scenarios, to observe current actions of competitors and potential partners and to identify future technology trends.

For this, the paper proposed the application of the concept of an observatory of trends, using as case study, the area of

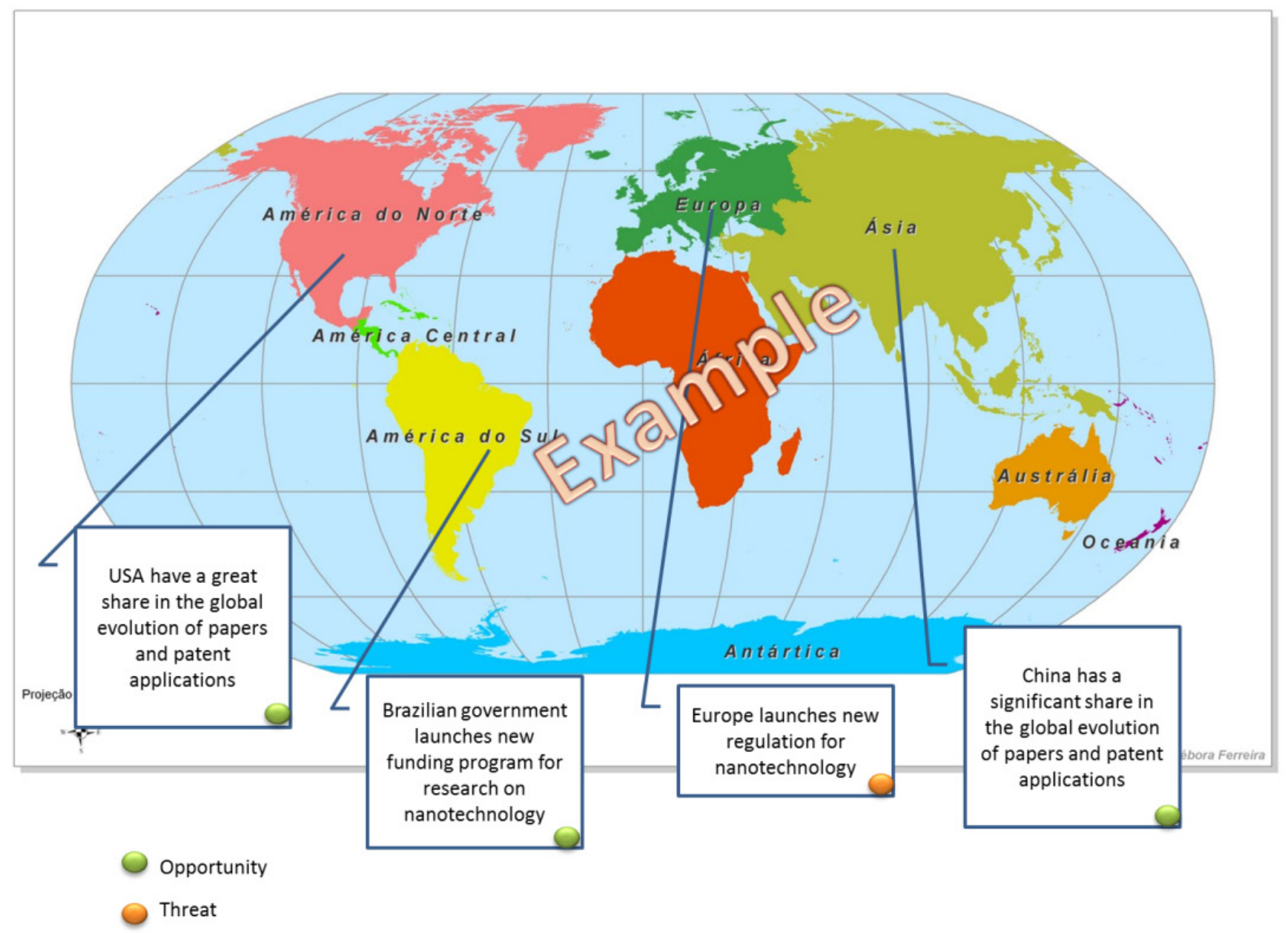

Figure 6. Summary table of constraints, movements of actors and opportunities/threats. Data based on:Authors' elaboration.

ISSN: 07 I8-2724. (http://www.jotmi.org)

Journal of Technology Management \& Innovation @ Universidad Alberto Hurtado, Facultad de Economía y Negocios. 
nanotechnology at CENPES, an emerging and multidisciplinary area in this research center.The observatory proposed is composed of a set of topics (variables/questions), sources of information, competitive technical intelligence and technological foresight techniques, etc., systematized in order to generate the necessary information in a suitable format for decision making in the context of technology management.

The observatory can provide information, such as: identification of new technologies, development of technological trajectories, mapping of potential partners, monitoring of actions of competitors, regulations and monitoring their impacts, identifying incentives and financing, among others. technology management, as example: the definition of technological strategies, the identification of technological partnerships (especially in the context of open innovation) and the construction of future vision for technology dimension, as well as the monitoring of the technological dimension of prospective scenarios, to observe signs and future trends.

As future actions, after structuring the model of observatory of trends in the area of nanotechnology, it is suggested to apply in other areas of CENPES, and it can also be conducted a comparison between an emerging area and a more mature area, in order to verify aspects in the model that should be customized according to the dynamics of each area.

The idea is that the observatory of trends can subsidize different processes in a R\&D business center, related to

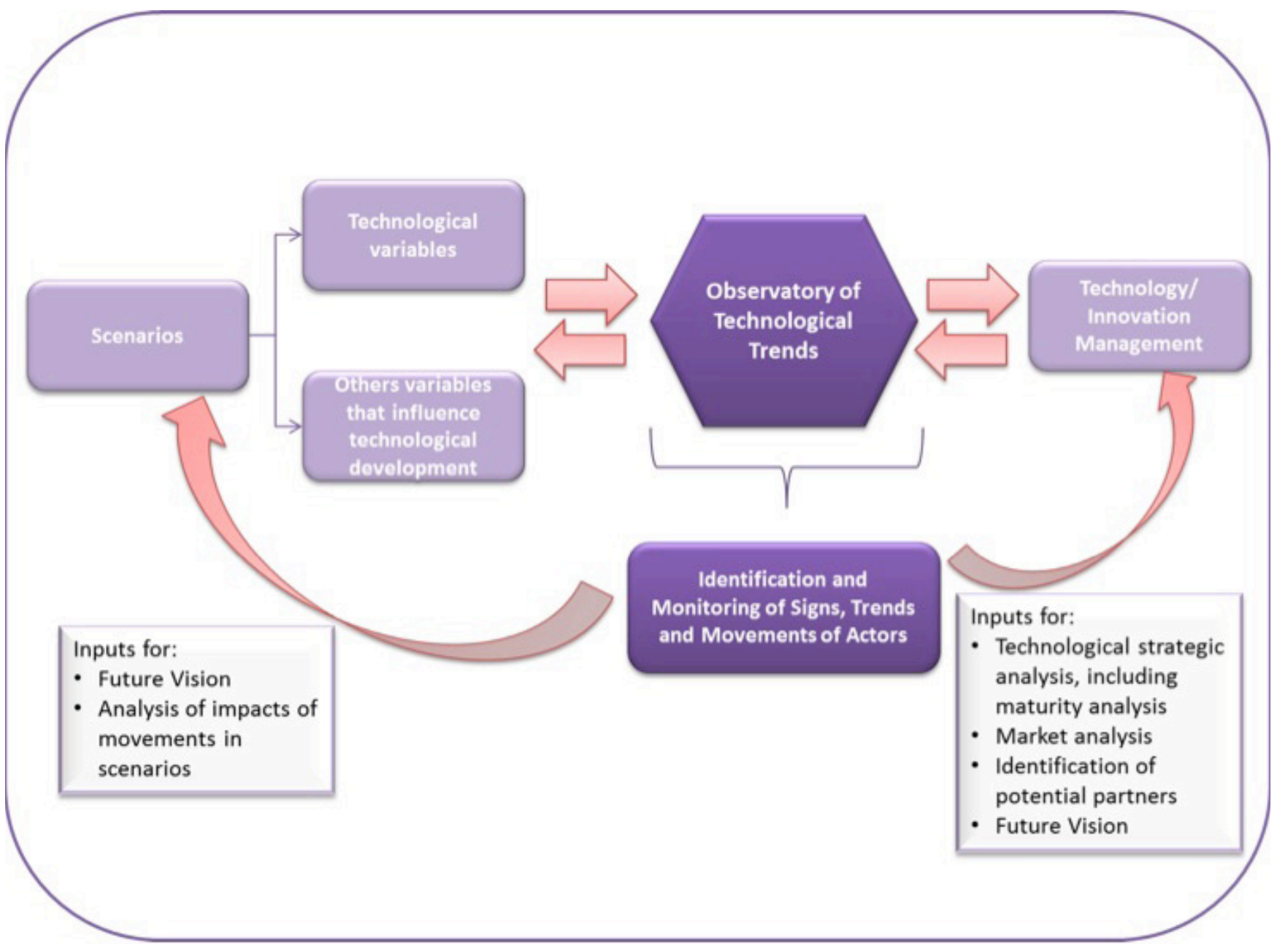

Figure 7. Interface between the Observatory of Trends and other processes. Data based on:Authors' elaboration.

ISSN: 07 I8-2724. (http://www.jotmi.org) 


\section{References}

AGÊNCIA Brasileira de Desenvolvimento Industrial - ABDI. (2010). Estudo Prospectivo Nanotecnologia, (Volume 20). http://www.abdi.com.br/Estudo/Estudo\%20Prospectivo\%20 de\%20Nanotecnologia.pdf. [Accessed June 20, 20I3].

ALVES, O. L. (2004). Nanotecnologia, nanociência e nanomateriais: quando a distância entre presente e futuro não é apenas questão de tempo. Parcerias Estratégicas, 18, 23-40. http://www.cgee.org.br/arquivos/pe_I8.pdf [Accessed June $5,2013]$.

ASHTON,W. B.; Klavans R.A. (1997). Keeping abreast of science and technology: technical intelligence for business. Battelle, Columbus.

ASHTON,W. B.; Hohhpf, B. (2009). Competitive technical intelligence. Competitive Intelligence Foundation, Alexandria.

COATES, J. F. (I 985). Foresight in Federal Government Policy Making. Futures Research Quarterly, I, 29-53.

COBURN, M. M. (1999). Competitive technical intelligence: a guide to design, analysis and action. American Chemical Society, Washington.

GEORGHIOU, L. (Ed.). (2008). The handbook of technology foresight: concepts and practice. Edward Elgar, Cheltenham.

GODET, M. (1987). Scenarios and strategic management. Butterworths Scientific, London.

IRVINE, J.; MARTIN, B. (1984). Foresight in Science. Sage, London.

KERR, C.I.V. et al. (2006). A conceptual model for technology intelligence. Int. J. Technol. Intel. Plan., 2 (I), 73-93. doi: I0.1504/IJTIP.2006.0105II. [Accessed May 10, 2013]

MELO, C. P.; Pimenta, M. (2004). Nanociências e nanotecnologia. Parcerias Estratégicas, 18, 9-2I. http://www.cgee.org. br/arquivos/pe_I8.pdf. [Accessed June 5, 2013]

Ministério de Ciência Tecnologia e Inovação - MCTI. (20I3). http://www.mct.gov.br. [Accessed February 22, 2013].

Ministério do Desenvolvimento, Indústria e Comércio Exterior - MDIC. (2013). http://www.desenvolvimento.gov.br/ sitio/. [Accessed February 22, 20I3].

MILLER, J. P. (2002). O milênio da inteligência competitiva. Bookman, Porto Alegre.
National Nanotechnology Advisory Panel - NNAP. (2005). The National Nanotechnology Initiative at five years:Assessment and recommendations of the national nanotechnology advisory panel. http://www.whitehouse.gov/sites/default/ files/microsites/ostp/pcast-nni-five-years.pdf. [Accessed June $5,2013]$.

PARREIRAS, V. M. A.; Antunes, A. M. S. (20I2). Aplicação de foresight e inteligência competitiva em um centro de P\&D empresarial por meio de um observatório de tendências: desafios e benefícios. Revista Gestão e Conexões, I (I). DOI: 10.1307I/regec.23 I7-5087.20I2.I.I.3908.55-73. [Accessed July 2, 2013].

Petróleo Brasileiro SA. - Petrobras. (20I3). Guia rápido de gestão de tecnologia na Petrobras.

Petróleo Brasileiro SA. - Petrobras. (2013). http://www. petrobras.com.br/pt/. [Accessed January 7, 20I3].

PORTER et al. (199I). Forecasting and Management of Technology.J.Wiley, New York.

TIDD, J.; Bessant, J.; Pavitt, K. (2008). Gestão da Inovação. Bookman, Porto Alegre.

United Nations Industrial Development Organization UNIDO. (2005). Technology Foresight Manual: Organization and methods. (Volume I) https://www.unido.org/foresight/ registration/dokums_raw/volumel_unido_tf_manual.pdf [Accessed April 10, 2013].

United Nations Industrial Development Organization UNIDO. (2005). Technology Foresight Manual: Technology foresight in action. (Volume 2). https://www.unido.org/foresight/registration/dokums_raw/volume2_unido_tf_manual. pdf. [Accessed April 10, 20I3]. 